\title{
NUMERICAL MODELING OF SHORT AND LONG TERM WAVES AND SURGES BY HURRICANE IRMA AND MARIA IN US VIRGIN ISLANDS
}

\author{
Nobuhito Mori, Kyoto University, mori@oceanwave.jp \\ Takenori Shimozono, University of Tokyo, shimozono@coastal.t.u-tokyo.ac.jp \\ Taro Arikawa, Chuo Univeristy, arikawa@civil.chuo-u.ac.jp \\ Daisuke Inazu, Tokyo University Marine Science Technology, inazud@m.kaiyodai.ac.jp \\ Tomoya Shimura, Kyoto University, shimura.tomoya.2v@kyoto-u.ac.jp \\ Andrew Kennedy, The University of Notre Dame, andrew.kennedy@nd.edu \\ Daniel Cox, Oregon State University,dan.cox@oregonstate.edu
}

\begin{abstract}
INTRODUCTION
Two powerful hurricanes successively passed close to US Virgin Islands in September 2017. Hurricane Irma developed into CAT5 with the lowest pressure around $914 \mathrm{hPa}$ on $5^{\text {th }}$ of September and passed north of USVI. Sequentially, CAT5 Hurricane Maria followed the similar track, but passed south of USVI (Figure 1). Two CAT5 hurricanes gave devastated damage along the Caribbean Islands. It is a rare event having two CAT5 with similar tracks within two weeks. This study presents hindcasts of waves and storm surge for the two hurricanes and discusses coastal damages with our survey data targeting on USVI.
\end{abstract}

\section{METHODOLOGY}

Wave and storm surge hindcasts were conducted for hurricane Irma and Maria. The adaptive mesh refinement model, GeoClaw, was used for storm surge modeling, while WaveWatchlll was used for wave modeling. The forcing to the models was given by satellite based hurricane track data by NOAA. Additionally, long-term extreme wave climate was analyzed by JRA-55 wave hindcasts and estimated return periods of two events around USVI.

A joint survey was conducted by NSF-Rapid and JSCE to measure run-up and inundation heights by optical level and GPS along the USVI coasts, St. Thomas, St. John and St. Croix islands. The run-up heights were estimated by the high resolution aerial photos in advance. The survey was conducted based on preliminary assessment by the numerical and photograph analysis.

\section{RESULTS}

The estimated maximum storm surge heights are $2.0 \mathrm{~m}$ at St. Thomas island and $2.5 \mathrm{~m}$ at St. Croix island. As the astronomical tide ranges about $30 \mathrm{~cm}$ around USVI, these are 6-8 times larger than the usual sea surface change. The maximum significant wave height, Hs, exceeded $12 \mathrm{~m}$ and may have reached up to $15 \mathrm{~m}$ depending on the locations and events as shown in Figure 2. As hurricane Irma and Maria passed north and south of USVI, combined two events generated extreme waves all around the islands. The geographical features of St. Thomas and St. Croix islands are characterized by steep and flat land, respectively, and they make different characteristics of coastal damages on the two islands. The two different hurricanes also gave a difference in damage characteristics.

The measured run-up heights around the rocky or cliffed coast reached 5-6 m at some locations. The maximum run-up of $6.4 \mathrm{~m}$ was observed at the northwest coast of St. Croix island. The estimated run-up heights by the aerial photo in advance were basically consistent to the measured heights. The analysis of aerial photos immediately after each event clarified coastal damages by the two hurricanes which could not be confirmed by the field survey. The combination of onsite measurements and aerial photo analysis gives details of hazard characteristics for Irma and Maria events.

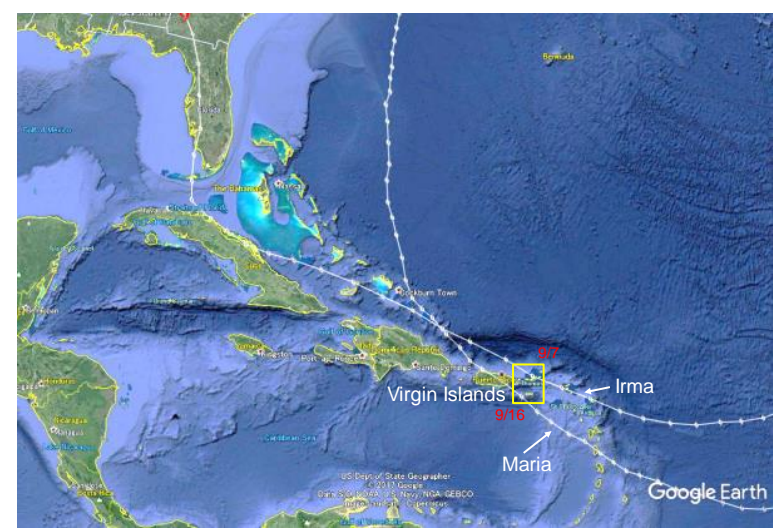

Figure 1 Tracks of two hurricanes

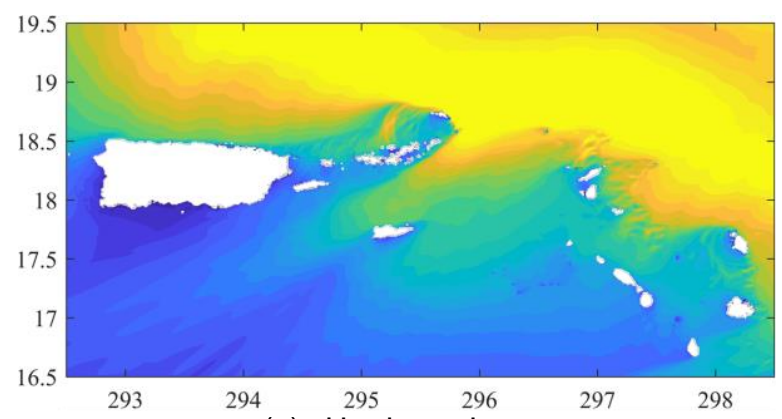

(a) Hurricane Irma

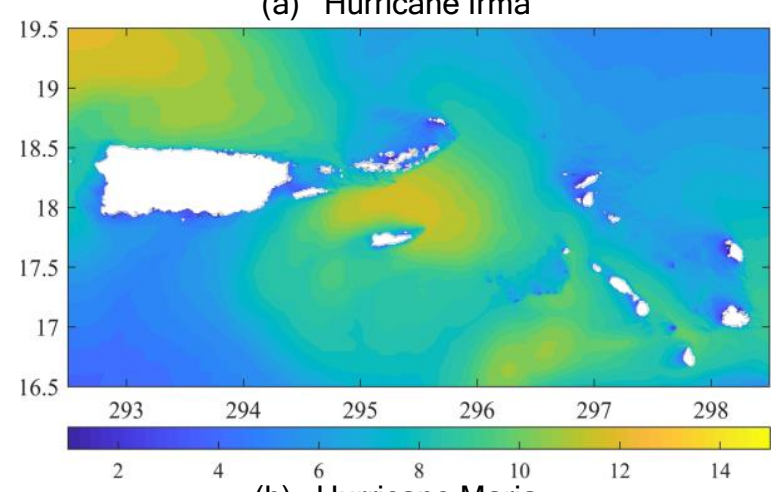

(b) Hurricane Maria

Figure 2 Maximum Hs around USVI (unit: $\mathrm{m}$ ) 